\title{
Resistência de Genótipos de Milho ao Ataque de Sitophilus zeamais Mots. (Coleoptera:Curculionidae)
}

\author{
Arlindo L. Boiça Jr. ${ }^{1}$, Fernando M. Lara ${ }^{1}$ e Flávio P. Guidi ${ }^{1}$ \\ ${ }^{1}$ Departamento de Entomologia e Nematologia, FCAV/UNESP, Rodovia Carlos \\ Tonanni km 5, 14870-000, Jaboticabal,SP.
}

An. Soc. Entomol. Brasil 26(3): 481-485 (1997)

\begin{abstract}
Resistance of Maize Genotypes to the Attack of Sitophilus zeamais Mots. (Coleoptera: Curculionidae)
\end{abstract}

\begin{abstract}
Evaluation of maize (Zea mays) genotypes resistance to Sitophilus zeamais Mots., in the laboratory, in no choice and free choice tests, indicated that the genotypes less attractive to the insect were C-701 and C-505 (8.5\% and $10.43 \%$ of the insects released), while the most attractive were C-525 and C606 (33.25\% and 21.72\%). The emergence of insects and weight grain consumption were lower on the genotypes C-511, C-505, C-525 and C-125 (5.0 insects and $0.1 \mathrm{~g} ; 8.1$ and $0.1 ; 8.5$ and $0.2 ; 9.9$ and 0.2 ) than on C-606, C-805, C701 and $\mathrm{C}-135$ (24.2 insects and $0.6 \mathrm{~g} ; 18.6$ and $0.5 ; 20.4$ and $0.5 ; 20.1$ and 0.5 ).
\end{abstract}

KEY WORDS: Insecta, host plant resistance, maize weevil.

RESUMO - Avaliação da resistência de genótipos de milho ao ataque de Sitophilus zeamais Mots., em condições de laboratório, em testes com e sem chance de escolha, indicaram que os genótipos menos atrativos ao inseto foram C-701 e C-505 (8,5\% e 10,43\% dos insetos liberados), enquanto que C-525 e C-606 (33,25\% e 21,72\%) foram os mais atrativos. Os genótipos C-511, C-505, C-525 e C-125 proporcionaram a emergência de menor número de insetos e de peso de grãos consumidos (5,0 insetos e $0,1 \mathrm{~g} ; 8,1$ e 0,$1 ; 8,5$ e 0,$2 ; 9,9$ e 0,2$)$, quando comparados ao C-606, C-805, C-701 e C-135 com maiores valores (24,2 insetos e $0,6 \mathrm{~g} ; 18,6$ e 0,$5 ; 20,4$ e 0,$5 ; 20,1$ e 0,5 respectivamente).

PALAVRAS-CHAVE: Insecta, resistência de plantas, gorgulho do milho.

Dentre as pragas que atacam os grãos do milho (Zea mays) armazenado, Sitophilus zeamais Mots. é uma das mais importantes, tendo em vista os danos quantitativos e qualitativos que acarretam (Rossetto 1966). Estes prejuízos são classificados em perdas de peso, desvalorização comercial dos grãos, perda do valor nutritivo, perda do poder germinativo das sementes,contaminação por ácaros e fungos, etc (Prates \& Frattini 1976).
Pela precariedade com que estes grãos são normalmente armazenados pelos agricultores, são necessários estudos de técnicas que dificultem naturalmente o ataque destes gorgulhos ao milho; assim, o uso de variedades resistentes surge como um método favorável.

Rossetto (1972) testou os genótipos de milho Duro cv. Cateto, Azteca e Maya e concluiu que, na forma de grãos debulhados, 
a cv. Azteca mostrou uma tendência em ser mais resistente que Cateto. Em outro estudo, Mallmann et al. (1988), testando a evolução do dano causado por $S$. zeamais, utilizaram 12 genótipos de milho incluindo híbridos comuns, doce, super doce e tipos "flowery". Testes de preferência com chance de escolha foram realizados e os grãos foram armazenados por 90, 120 e 150 dias. Verificaram que os genótipos SMD-I, SIN-I, Pozo Amarillo (doces) e o Hawai (Superdoce) tiveram os maiores níveis de infestação, porém os grãos apresentaram a menor perda de peso. Entretanto a germinação desses genótipos foi menor devido ao dano causado pelo inseto.

Tipping et al. (1988) realizaram estudos com 56 linhagens de milho dentado, adaptados ao cinturão do milho norte americano, onde estas foram testadas quanto a não-preferência para oviposição por $S$. zeamais. Pelos resultados os autores concluíram que B 37, B 68, H 84, R 805, T 220 e Va 26 mostraram ser mais resistente, enquanto A 619, B 73, C 103, H 95, Pa 91 e W 117 destacaram como suscetíveis.

Kang (1991) na Louisiana, E.U.A., através da avaliação de vários genótipos de milho por um período de quatro anos para resistência ao Sitophilus spp., concluiu que o cv. PI91414, também conhecidos por Filipinas, apresentou resistência absoluta ao ataque do inseto, não tendo sequer um único grão danificado. Esta planta introduzida é conhecida por possuir níveis muito baixos de aflatoxina B1.

Em Jaboticabal, SP, L.M. Luccin (não publicado) relata que o número de $S$. zeamais emergidos foi menor nos genótipos C - 125 e C - 505, quando aplicou-se nas plantas potássio, para C - 505 com nitrogênio e C$701 \mathrm{com}$ a presença de nitrogênio ou fósforo. Os tratamentos C - 125 sem NPK, C - 505 com PK e C - 505 com NPK, proporcionaram menores médias de peso seco de alimento consumido.

O trabalho teve por objetivo avaliar a resistência de diferentes genótipos de milho frente ao ataque de $S$. zeamais, em teste com e sem chance de escolha, em laboratório.

\section{Material e Métodos}

Os experimentos foram conduzidos em 1994, no Laboratório de Resistência de Plantas a Insetos, do Departamento de Entomologia e Nematologia da Faculdade de Ciências Agrárias e Veterinárias de Jaboticabal,UNESP.

Teste sem Chance de Escolha. Os genótipos testados foram: C-125, C-135, C-425, C484, C-501, C-505, C-511, C-525, C-555, C606, C-701, C-742, C-801 e C-805, da Cargill Agrícola S.A.. Inicialmente, pesaram-se $10 \mathrm{~g}$ de sementes de cada genótipo, os quais foram colocados em caixas plásticas de $24,19 \mathrm{~cm}^{3}$, liberando-se em seu interior 20 gorgulhos recém-emergidos (Rossetto 1972). Cada caixa correspondeu a uma parcela experimental e foram realizadas 10 repetições. As caixas permaneceram em local controlado com temperatura ambiente de $28^{\circ} \mathrm{C}$ e fotofase de 12 horas, sendo que os grãos apresentavam umidade entre 12 e $13 \%$. Estes insetos permaneceram nas caixas por sete dias, após o que foram retirados. Foram avaliados: número de insetos emergidos, ciclo biológico de ovo a adulto e peso de grãos consumidos.

Teste com Chance de Escolha. Baseando nos resultados do teste anterior, utilizaram-se os genótipos C-125, C-505, C-511, C-525 (resistentes), C-606 e C-701 (suscetíveis). As caixas plásticas (sem tampa) foram dispostas no interior da bandejas pretas de $30 \mathrm{~cm}$ de diâmetro e $5 \mathrm{~cm}$ de altura, e ficando o bordo superior das caixas à mesma altura da superfície de uma placa de isopor. No centro da bandeja liberaram-se 120 gorgulhos recémemergidos, colocando-se sobre esta, outra bandeja do mesmo tamanho, com o bordo invertido, selando-se a junção por fita adesiva. Todo o conjunto foi repetido por 10 vezes. Após 24 horas da liberação, abriram-se as bandejas e contou-se o número de insetos atraídos pelos genótipos. O delineamento experimental nos dois testes, foi o de blocos 
inteiramente casualizado sendo as médias comparadas pelo teste de Tukey $(\mathrm{P} \leq 0,05)$

\section{Resultados e Discussão}

Teste sem Chance de Escolha. Ocorreram diferenças significativas para o número de insetos emergidos, sendo que os genótipos C-511, C-505 e C-525 proporcionaram menor emergência de insetos, quando comparados aos genótipos C-606 e C-701, evidenciando naqueles, a presença de algum fator de resistência (Tabela 1). Com relação ao genótipo C-505, L.M. Luccin (não publicado) em teste semelhante, obteve também um menor número de gorgulho emergidos em grãos de milho, porém quando aplicou-se médias apresentaram pouca variação (entre 41,2 e 51,4 dias). Esses dados foram superiores àqueles obtidos por Rossetto (1972) com média de 34 dias e por Puzzi (1986) com valores entre 28 e 35 dias, possívelmente devido a influência dos genótipos e condições ambientais diferentes.

O consumo de grãos pelos insetos diferiu significativamente em função dos diferentes genótipos (Tabela 1). Os menores valores médios foram verificados para os genótipos C-511 (0,1g), C-505 (0,1g), C-525 (0,2g) e C-125 (0,2g), sugerindo serem os menos adequados ao consumo alimentar dos insetos. Fato semelhante foi observado por L.M. Luccin (não publicado) para os genótipos C 505 e C - 125, quando aplicou-se NPK no

Tabela 1. Número médio ( \pm EP) de Sitophilus zeamais emergidos, ciclo biológico de ovo a adulto e peso de grãos consumidos, obtidos em genótipos de milho, em teste sem chance de escolha.

\begin{tabular}{lccc}
\hline Genótipos & $\begin{array}{c}\text { Número de insetos } \\
\text { emergidos }\end{array}$ & $\begin{array}{c}\text { Ciclo biológico ovo a } \\
\text { adulto (dias) }\end{array}$ & $\begin{array}{c}\text { Peso de grãos } \\
\text { consumidos }(\mathrm{g})^{1}\end{array}$ \\
\hline C-606 & $24,2 \pm 3,28 \mathrm{a}$ & $47,1 \pm 0,71$ & $0,6 \pm 0,07 \mathrm{a}$ \\
C-701 & $20,4 \pm 2,44 \mathrm{ab}$ & $47,2 \pm 0,55$ & $0,5 \pm 0,06 \mathrm{abc}$ \\
C-135 & $20,1 \pm 2,48 \mathrm{abc}$ & $50,2 \pm 1,68$ & $0,5 \pm 0,05 \mathrm{abc}$ \\
C-805 & $18,6 \pm 1,82 \mathrm{abc}$ & $47,6 \pm 0,73$ & $0,5 \pm 0,05 \mathrm{ab}$ \\
C-484 & $16,5 \pm 3,22 \mathrm{abcd}$ & $45,6 \pm 0,82$ & $0,4 \pm 0,08 \mathrm{abcd}$ \\
C-742 & $15,0 \pm 3,06 \mathrm{abcd}$ & $49,1 \pm 1,19$ & $0,3 \pm 0,06 \mathrm{abcde}$ \\
C-801 & $14,8 \pm 1,19 \mathrm{abcd}$ & $47,5 \pm 0,65$ & $0,3 \pm 0,05 \mathrm{abcde}$ \\
C-555 & $13,0 \pm 1,59 \mathrm{abcde}$ & $49,2 \pm 1,21$ & $0,3 \pm 0,05 \mathrm{bcde}$ \\
C-425 & $11,2 \pm 2,27 \mathrm{bcde}$ & $46,8 \pm 0,82$ & $0,2 \pm 0,05 \mathrm{bcde}$ \\
C-125 & $9,9 \pm 1,71 \mathrm{bcde}$ & $41,2 \pm 4,23$ & $0,2 \pm 0,06 \mathrm{cde}$ \\
C-501 & $9,6 \pm 1,61 \mathrm{bcde}$ & $51,4 \pm 1,09$ & $0,2 \pm 0,04 \mathrm{bcde}$ \\
C-525 & $8,5 \pm 1,74 \mathrm{cde}$ & $47,9 \pm 1,46$ & $0,2 \pm 0,04 \mathrm{cde}$ \\
C-505 & $8,1 \pm 1,67 \mathrm{de}$ & $43,6 \pm 4,48$ & $0,1 \pm 0,04 \mathrm{de}$ \\
C-511 & $5,0 \pm 1,88 \mathrm{e}$ & $43,6 \pm 4,86$ & $0,1 \pm 0,04 \mathrm{e}$ \\
\hline
\end{tabular}

${ }^{1}$ Médias seguidas de mesma letra, não diferem estatisticamente pelo teste de Tukey $(\mathrm{P} \leq 0,05)$.

potássio ou nitrogênio às plantas no campo.

O ciclo biológico, de ovo a adulto, de $S$. zeamais alimentados em grãos dos diversos genótipos de milho (Tabela 1), não foi significativamente afetado, sendo que as campo para o primeiro, e, ausência para o segundo, o que de maneira geral influenciou a emergência dos gorgulhos. Por outro lado, com maiores valores destacam C-606 $(0,6 \mathrm{~g})$ e C-805 (0,5g). 


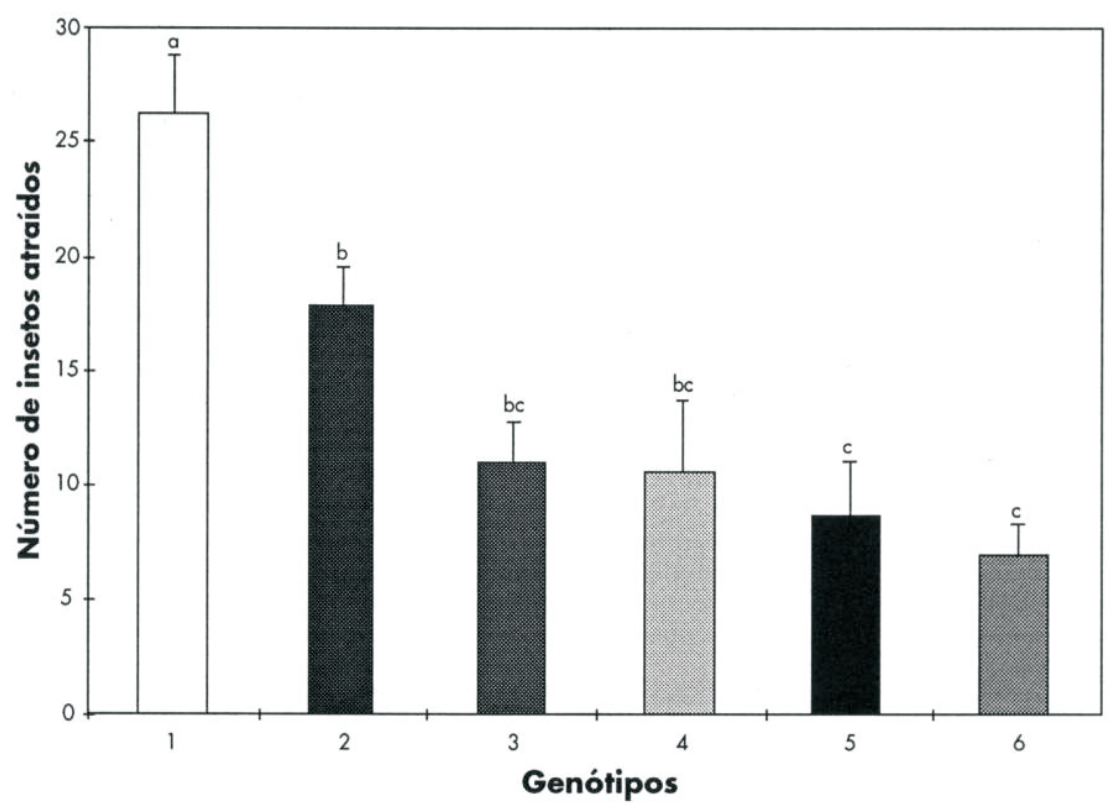

Figura 1. Número médio $( \pm \mathrm{EP})$ de Sitophilus zeamais atraídos por seis genótipos de milho, em teste com chance de escolha $(1=\mathrm{C}-525 ; 2=\mathrm{C}-606 ; 3=\mathrm{C}-125 ; 4=\mathrm{C}-511 ; 5=$ C-505; 6= C-701). Médias seguidas pela mesma letra não diferem significativamente pelo teste de Tukey $(\mathrm{P} \leq 0,05)$.

Comparando-se os valores obtidos entre o número de insetos emergidos e o consumo de grãos pelos gorgulhos nos genótipos, verifica-se que os genótipos C-511, C-505, C-525 e C-125 apresentaram menor número de insetos emergidos e consumo de grãos, sugerindo apresentarem resistência ao inseto. Opostamente, os genótipos C-606, C-805, C701 e C-135 proporcionaram os maiores valores para ambos parâmetros, caracterizando a suscetibilidade destes materiais ao S. zeamais.

Teste com Chance de Escolha. O número médio de $S$. zeamais que selecionaram os genótipos C-701 e C-505 foi menor que àqueles que selecionaram C-525 e C-606 (Fig. 1 ), evidenciando menor atratividade naqueles materiais. Este fato possivelmente deve estar relacionado a algumas causas químicas, como por exemplo a liberação, pelos grãos, de algumas substâncias atrativas aos gorgulhos para oviposição e/ou alimentação, uma vez que estímulos físicos, como a côr, não tem revelado qualquer relação com a resistência de genótipos de milho à praga em estudo, segundo Ramalho (1975).

Comparando-se os dados de ensaio anterior com o atual (Tabela 1 e Fig. 1), nota-se que os genótipos C-511, C-505 e C-125 encontram-se entre os menos atrativos para os insetos e também apresentaram menores médias do número de insetos emergidos e peso de grãos consumidos, sugerindo serem estes materiais menos adequados ao desenvolvimento de $S$. zeamais, configurando assim, a existência de algum fator de resistência provavelmente do tipo não-preferência para oviposição e/ou alimentação.

O genótipo C-701 apresentou pouca 
atração aos gorgulhos (Fig.1), porém elevado número de insetos emergidos e peso de grãos consumidos (Tabela 1), caracterizando ser um material suscetível. O genótipo C-606 comportou-se como altamente suscetível, pois apresentou elevado número de insetos atraídos, emergidos e peso de grãos consumidos.

Com os resultados obtidos, pode-se concluir, de forma geral, que os genótipos C511, C-505 e C-125 são resistentes a $S$. zeamais, enquanto o C-606 é o mais suscetível.

\section{Agradecimentos}

Os autores agradecem a colaboração do Eng. Agr. Ary de Toledo Mello Fo, pesquisador da Cargill Agricola S.A., pelo fornecimento das sementes dos genótipos testados e ao CNPq pelas Bolsas de Produtividade em Pesquisa dos dois primeiros autores.

\section{Literatura Citada}

Kang, M.S. 1991. Absolute resistense to weevils. Maize Genetics Cooperation News Letter, Baton Rouge 65:22.

\section{Mallmann, I.L., L. Storck \& D. Link. 1988.} Evaluation of the damage by Sitophilus zeamais in grains of differente types of maize. Rev. Cent. Ciênc. Rurais 18:209218.
Principais pragas dos grãos armazenados e recomendações para seu controle. Campinas; CATI, Bol. Téc. 89, 26p.

Puzzi, D. 1986. Abastecimento e armazenagem de grãos. Campinas, Editora Instituto Campineiro de Ensino Agrícola, 603p.

Ramalho, F. S. 1975. Resistência de raças, híbridos e variedades de milho em palha e debulhado, ao ataque de Sitophilus zeamais Motschulsky, 1855. Dissertação de mestrado, ESALQ-USP, Piracicaba, $122 \mathrm{p}$.

Rossetto, C.J. 1972. Resistência de milho à pragas da espiga Helicoverpa zea (Boddie), Sitophilus zeamais Motschulsky e Sitotroga cerealella (Oliver). Tese de doutorado, ESALQUSP, Piracicaba, 111p.

Rossetto, C.J. 1966. Sugestões para armazenamento de grãos no Brasil. O Agronômico 18:38-51.

Tipping, P.W., J.G. Rodriguez, C.G. Poneleit \& D.E. Legg. 1988. Resistence of dent corn inbred lines to oviposition by the maize weevill. Kans. Entomol. Soc. 61:131-134.

Prates, H.S. \& J.A. Frattini. 1976. Recebido em 27/02/96. Aceito em 24/09/97. 